\title{
The Pattern of Pacemaker Induced Tricuspid Regurgitation
}

\author{
Ziad Drabaa, Mohammed Holy, Marwan Nemri
}

Adult Cardiology Department/ Queen Alia Heart Institute/ King Hussein Medical Center.

\begin{abstract}
Objective: To determine the frequency and significance of tricuspid regurgitation in patients who underwent a single lead permanent pacemaker implantation.

Methods: This is a retrospective study conducted at Queen Alia Heart Institute in AmmanJordan during the period 2006 to 2009. A group of 67 patients who had a single lead permanent pacemaker implantation in that period was involved in the study.

For each patient a transthorasic two dimensional echocardiography was done 6 - 12 months after insertion of the pacemaker; checking for the presence of tricuspid regurgitation and its degree.
\end{abstract}

Results: Males constituted $68.7 \%$ of the study sample.

The majority (91\%) of patients in the study group had their permanent pacemaker due to complete heart block.

Tricuspid regurgitation following insertion of permanent pacemaker was found to be mild in the majority $(92.5 \%)$ of patients.

Significant and gross tricuspid regurgitation was not common and found only in males.

Conclusion: Tricuspid regurgitation after permanent pacemaker is usually mild in short term follow up. However echocardiography check up is recommended to monitor the degree of tricuspid regurgitation progression in chronic term particularly in the elderly males and smokers.

\section{Introduction}

Theoretically, tricuspid regurgitation (TR) was considered as a potential complication of permanent lead implantation. (Morgan DE et al,1986) However mild TR is a relatively common $^{\text {(Paniagua D et al,1998) }}$ and known sequel to transvenous right ventricular pacemaker lead, as a result of valve malcoaptation and interference with valve closure. ( Lin G\& Nishimura RA et al,2005)

This explains the increasing degree of TR by increasing the number of ventricular leads used in pacing. ( Postaci N et al,1995\& de Cock CC et al,2000 )

Nevertheless, severe symptomatic TR can occur in rare cases, secondary to, for example, impingement of the tricuspid valve by the pacing lead, (Champagne J et al,2002) or from leaflet adhesion to the pacemaker lead. (Iskandar SB et al,2006)
Moreover, an increase in TR grade was documented in patients with right ventricular pacing even without evidence of changes in the right ventricular area or evidence of interference with leaflet closure by the lead ${ }^{\text {(Mordehay } \mathrm{V} \text { et al,2010) }}$

Some reports ( Lin G\& Nishimura RA et al,2005) documented an increase in the prevalence of permanent pacemaker induced severe TR and the need for surgical treatment to correct this complication.

\section{Patients and methods}

This retrospective study was conducted at Queen Alia Heart Institute in Amman Jordan, during the period January, 2006 to December, 2009. Sixty seven adult patients who underwent a single lead permanent pacemaker implantation were 
involved in the study. All patients had their two - dimensional echocardiography with color - flow doppler study in 6 to 12 months after the date of pacemaker insertion. Each echocardiography was examined for the presence of TR and its severity. The degree of tricuspid valve insufficiency was assessed using four gradual scale: grade I (mild), grade II and III (moderate) and grade IV (severe).

The data collected was analyzed to check for the prevalence of tricuspid regurgitation and its severity. Pediatric age group was excluded from the study.

\section{Results}

Over the period from 2006 to 2009, a random group of patients who had a single lead permanent pacemaker were included in this study, with a total number of 67 patients. Patients ranged from 32 to 75 years of age.

Males constituted the majority of patients: 46 patients $(68.7 \%)$, while females were only 21 patients $(31.3 \%)$, as can be seen in table 1 .

Complete heart block (CHB) was the reason for pacemaker implantation in the majority of patients $(91 \%)$, whereas a minority (9\%) had their pacemaker due to symptomatic second degree heart block $\left(2^{\circ}\right.$ AVB), as observed in table 2 .

Table 3 shows that the majority $(92.5 \%)$ of patients with a single lead pacemaker was found to have mild degree of TR, grade I in 30 patients and grade II in 32 patients. Moderately severe and severe TR was found in a minority $(7.5 \%)$ of the included sample; only five patients had significant TR. They were all males, smokers and elderly ranged from 70 to 75 years of age.

\section{Discussion}

Since the early literature, (Paniagua D et al,1998\& Postaci N et al,1995\& Sakai M et al,1987 ) many papers described the presence of tricuspid insufficiency in permanently paced patients by means of echocardiographyic techniques, although other few reports (Shandling AH et al,1989\& Leibowitz DW et al,2000 ) did not confirm these results.

Our study showed that severe TR is not common, while damage to the tricuspid valve by permanent pacemaker lead may result in severe symptomatic TR that requires surgical correction was documented. ( Lin G\& Nishimura RA et al,2005)

On the other hand, it was reported ${ }^{\text {(Mordehay V et }}$ al,2010) that active right ventricular pacing per se is associated with a significant increase in TR grade that is not caused by acute changes in right ventricular area or leaflet damage and closure interference by the pacing lead.

Mostly mild degree of TR in the study sample raises the question of under estimation, because even in experienced echocardiographic laboratories, the detection of significant tricuspid insufficiency may be missed due to the acoustic shadows from the pacemaker wires and the suboptimal visualization of the regurgitant jet.

The finding of severe TR in mainly elderly males who are smokers requires examination of other added factors, like for example, chronic lung disease and

secondary pulmonary hypertension that may have contributed to further increase the severity of tricuspid regurge. (Weitenblum E et $\mathrm{al}, 2003)$

Our study did not include children with permanent pacemaker who demonstrated small, but statistically significant change in tricuspid regurgitation. (Webster G et al,2008)

One other explanation that TR was mostly mild in our study is that, patients involved ,had their pacemakers with only a single lead trans- tricuspid as more frequent and higher degree of TR was observed in patients with two leads in the right ventricle, (Postaci $\mathrm{N}$ et al,1995) although other 
reports ${ }^{(\text {Celiker } \mathrm{C} \text { et al,2004) }}$ showed that the number of leads does not have an additional negative effect or right ventricular and tricuspid valve function.

Patients with transvenous leads for other devices, like implantable cardioverter defibrillator (ICD) were excluded from the study, that could contribute to lower ratio of severe TR in our results, because it was reported $^{(\mathrm{Kim} J}$ et al,2008) that patients with ICDs had a higher rate of TR worsening compared with patients with permanent pacemaker.

Our conclusion that TR is usually mild post transvenous right ventricular pacemaker single lead, was in agreement with other reported studies, ( Leibowitz DW et al,2000\& Kucukarslan $\mathrm{N}$ et al, 2006 ) specially in the short term follow up. Whereas severe significant TR was well documented $^{\text {(Paniagua D et al,1998\& Iskandar SB et al,2006 ) }}$ in long term (years) monitoring in patients with permanent pacemaker.

It is no exaggeration if the authors suggest that patients with transvenous right ventricular leads should have regular long term follow up and echocardiographic examination looking for TR, in addition to encourage medical people to use other

modalities in diagnosing early TR like transesophageal and three - echocardiography. $_{\text {et }}^{\text {dimsion }} \underset{\text { al,2008) }}{\text { Seo }}$

Table 1: Distribution of patients according to sex

\begin{tabular}{|l|l|l|}
\hline Sex & No. & $\%$ \\
\hline Males & 46 & 68.7 \\
\hline Females & 21 & 31.3 \\
\hline Total & 67 & 100 \\
\hline
\end{tabular}

Table 2: Distribution of patients in respect to reason for pacing

\begin{tabular}{|c|c|c|c|}
\hline Reason for pacing & No. of Males & No. of females & Total \\
\hline CHB & 43 & 18 & $61(91 \%)$ \\
\hline 2 AVB & 3 & 3 & $6(9 \%)$ \\
\hline
\end{tabular}

Table 3: The pattern of tricuspid regurgitation in the study group patients

\begin{tabular}{|l|l|l|l|}
\hline \multicolumn{1}{|c|}{ Severity of TR } & \multicolumn{1}{c|}{ No. of males $(\%)$} & \multicolumn{1}{c|}{ No. of females (\%) } & \multicolumn{1}{c|}{ Total (\%) } \\
\hline Grade I & $18(39.1 \%)$ & $12(57.1 \%)$ & $30(44.8 \%)$ \\
\hline Grade II & $23(50.0 \%)$ & $9(42.9 \%)$ & $32(47.7 \%)$ \\
\hline Grade III & $4(8.7 \%)$ & - & $4(6 \%)$ \\
\hline Grade IV & $1(2.2 \%)$ & - & $1(1.5 \%)$ \\
\hline Total & $46(100 \%)$ & $21(100 \%)$ & $67(100 \%)$ \\
\hline
\end{tabular}




\section{References}

Celiker C, Kucukoglu MS, Arat-Ozkan A, Yazicioglu N, Uner S(2004): Right ventricular and tricuspid valve function in patients with two ventricular pacemaker leads. Japanese Heart Journal.,45:103-108.

Champagne J, Poirier P, Dumesnil JG, Desaulniers D, Boudreault JR, O'Hara G, Gilbert M, Philippon F(2002): Permanent pacemaker lead entrapment: role of the transesophageal echocardiography . Pacing Clin Electrophysiol.,25:1131-1134.

De Cock CC, Vinkers M, Van Campe LC, Verhorst PM, Visser CA(2000): Long-term outcome of patients with multiple ( $>$ or $=3$ ) noninfected transvenous leads: a clinical and echocardiographic study. Pacing Clin Electrophysiol.,23:423-426.

Iskandar SB, Ann Jackson S, Fahrig S, Mechleb BK, Garcia ID(2006): Tricuspid valve malfunction and ventricular pacemaker lead: case report and review of the literature. Echocardiography.,23:692-697.

Kim J, Spevack D, Tunick P, Bullinga J, Kronzon I, Chinitz L, Reynolds H(2008): The effect of transvenous pacemaker and implantable cardioverter defibrillator lead placement on tricuspid valve function: An observational study. J Am Soc Echo - JASE .,21:284-287.

Kucukarslan N, Kirilmaz A, Ulusoy E, Yokusoglu M, Gramatnikovski N, Ozal E, Tatar H(2006): Tricuspid insufficiency does not increase early after permanent implantation of pacemaker leads. Journal of Cardiac Surgery, 21:391-394.

Leibowitz DW, Rosenheck S, Pollack A, Geist M, Gilon $\mathbf{D}(2000)$ : Transvenous pacemaker leads do not worsen tricuspid regurgitation: A prospective echocardiographic study. Cardiology,93: 74-77.

Lin G, Nishimura RA, Connolly HM, Dearani JA, Sundt TM III, Hayes DL(2005): Severe symptomatic tricuspid valve regurgitation due to permanent pacemaker or implantable cardioverter-defibrillator leads. $J$ Am Coll Cardiol;45:1672-1675.

Mordehay V, Jairo K, Yaron S, Roman N, Idit Y, Daniel W, Daniel M, Boris $\mathrm{S}$, Alexander S(2010):Right ventricular pacing increases tricuspid regurgitation grade regardless of the mechanical interference to the valve by the electrode. European Journal of Echocardiography, 11:550-553.

Morgan DE, Norman R, West RO, Burggraf G(1986): Echocardiographic assessment of tricuspid regurgitation during ventricular demand pacing.Am J Cardiol 58:1025-1029.

Paniagua D, Aldrich HR, Lieberman EH, Lamas GA, Agatston AS(1998): Increased prevalence of significant tricuspid regurgitation in patients with transvenous pacemaker leads. Am J Cardiol.,82:1130-1132.

Postaci N, Eksi K, Bayata S, Yesil M(1995): Effect of the number of ventricular leads on right ventricular hemodynamics in patients with permanent pacemaker. Angiology;46:421-424.

Sakai M, Ohkawa S, Ueda K, Kin H, Watanabe C, Matsushita S, Kuramoto K, Sugiura M, Takahashi T, Takenaka K(1987): Tricuspid regurgitation induced by transvenous right ventricular pacing: echocardiographic and pathological observations. J Cardiol.,17:311-320.

Seo Y, Ishizu T, Nakajima H, Sekiguchi Y, Watanabe S, Aonuma K(2008): Clinical utility of 3-dimensional echocardiography in the evaluation of tricuspid regurgitation caused by pacemaker leads. Circ J.,72:1465-1470.

Shandling AH, Lehmann KG, Atwood E, Andersh S, Gardin J(1989): Prevalence of catheter-induced valvular regurgitation as determined by Doppler echocardiography. Am J Cardiol.,63:1369-1374.

Webster G, Margossian R, Alexander ME, Cecchin F, Triedman JK, Walsh EP, Berul CI(2008): Impact of transvenous ventricular pacing leads on tricuspid regurgitation in pediatric and congenital heart disease patients. $J$ Interv Card Electrophysiol.,21:65-68.

Weitenblum E(2003):Chronic cor pulmonale. Heart, 89:225-230. 


\title{
نمط الارتداد في الصمام ثلاثي الثرفات الناتج عن زراعة جهاز منظم ضريات القلب
}

\author{
د.زياد الضرابعة ود. محمد هولي ود.مروان النمري
}

مركز الملكة علياء لأمر اض وجراحة هولة القلب_الأردن

\section{هدف الدراسة وملخصها:}

تحديد معدل ومدى حدوث الارتداد عبر الصمام ثلاثي الثرفات و أهميته في المرضى الذين تم

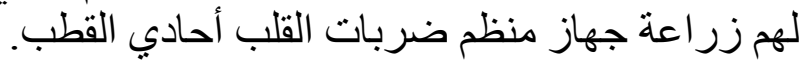

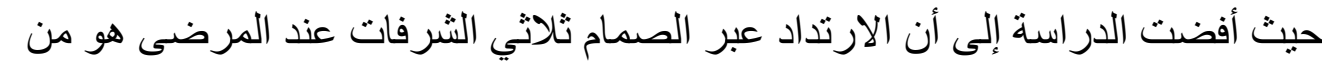

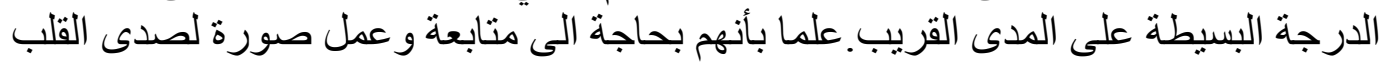
لمعرفة مدى حدوث هذا الارتداد على المدى البعيد خاصة عند الذكور كبار السن و المدخنين. 